\title{
Accuracy of computer-guided surgery for dental implant placement in fully edentulous patients: A systematic review
}

\author{
Daniel Amaral Alves Marlière ${ }^{1}$, Maurício Silva Demétrio ${ }^{1}$, Leonardo Santos Picinini ${ }^{2}$, \\ Rodrigo Guerra De Oliveira ${ }^{2}$, Henrique Duque De Miranda Chaves Netto ${ }^{1}$
}

Correspondence: Dr. Daniel Marlière

Email: ctbmf.marliere@gmail.com
'Department of Clinical Dentistry, Juiz de Fora Dental School, Federal University of Juiz de Fora, Juiz de Fora, Brazil,

${ }^{2}$ Division of Implant Dentistry, Faculty of Medical Science and Health - SUPREMA and HMTJ, Juiz de Fora, Brazil

\section{ABSTRACT}

Assess clinical studies regarding accuracy between virtual planning of computer-guided surgery and actual outcomes of dental implant placements in total edentulous alveolar ridges. A PubMed search was performed to identify only clinical studies published between 2011 and 2016, searching the following combinations of keywords: "Accuracy AND Computer-Assisted Surgery AND Dental Implants." Study designs were identified using the terms: Case Reports, Clinical study, Randomized Controlled Trial, Systematic Reviews, Meta-Analysis, humans. Level of agreement between the authors in the study selection process was substantial $(k=0.767)$, and the study eligibility was considered excellent $(k=0.863)$. Seven articles were included in this review. They describe the use of bone and muco-supported guides, demonstrating angular deviations cervically and apically ranging from (minimum and maximum means), respectively, 1.85-8.4 $\left(^{\circ}\right.$ ), 0.17-2.17 (mm), and 0.77-2.86 (mm). Angular deviations obtained most inaccuracy in maxila. For cervical and apical deviations, accuracy was preponderantly lower in maxilla. Despite the similar deviations measurement approaches described, clinical relevance of this study may be useful to warn the surgeon that safety margins in clinical situations.

Key words: Accuracy, computer-aided manufacturing, computer-aided planning, dental implants

\section{INTRODUCTION}

Conventional dental panoramic tomography and periapical radiography were often performed with the patient wearing a template simulating the preoperative prosthetic design. Such imaging techniques, however, do not provide full three-dimensional (3D) information on the patient's anatomy. In addition, conventional surgical guides made from the diagnostic plaster casts to direct the entry point and angulation of the drills

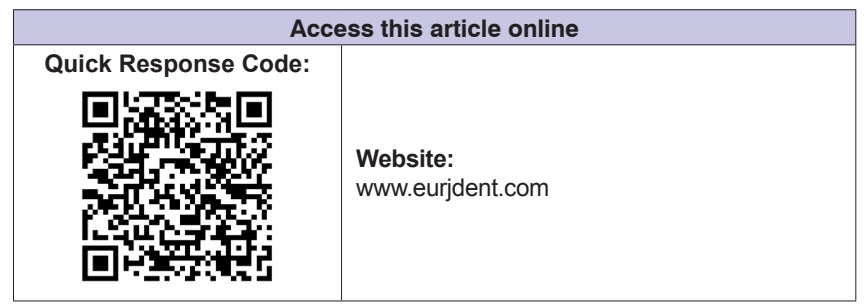

for osteotomy do not strictly follow the underlying anatomical structures nor do they provide accurate $3 \mathrm{D}$ guidance. ${ }^{[1]}$

Currently, there have been major technological developments in diagnostic imaging methods and turned more accessible. The introduction of computed

This is an open access article distributed under the terms of the Creative Commons Attribution-NonCommercial-ShareAlike 3.0 License, which allows others to remix, tweak, and build upon the work non-commercially, as long as the author is credited and the new creations are licensed under the identical terms.

For reprints contact: reprints@medknow.com

How to cite this article: Marlière DA, Demétrio MS, Picinini LS, De Oliveira RG, Chaves Netto HD. Accuracy of computer-guided surgery for dental implant placement in fully edentulous patients: A systematic review. Eur J Dent 2018;12:153-60.

DOI: 10.4103/ejd.ejd_249_17 
tomography images, including cone-beam computed tomography (CBCT), improved the outcome of implant-based treatments since it allows preoperative diagnosis with excellent quality and less exposure of the patients to radiation. ${ }^{[2]}$ When CBCT was associated with computer-aided design and manufacturing (CAD/CAM) provided surgical planning in both virtual and 3D environments, providing the practitioner with a realistic view of the patient's bony anatomy, thus permitting a virtual execution of the surgery in an ideal and precise prosthetically driven manner. ${ }^{[3]}$ This approach has been introduced to transfer virtual planning to the clinical procedure, allowing for less invasive surgeries, adequate implant placement, reduction of postoperative discomfort, and fabrication of prosthetic structures before surgical procedures. ${ }^{[4]}$

Hämmerle et al. ${ }^{[5]}$ published the consensus on indications and clinical recommendations for CAD/CAM procedures in implant dentistry. In this consensus, they defined the term guided surgery, which consists in the use of a static guide that reproduces the virtual position of the implant to allow for intraoperative real-time tracking of the drills according to the planned trajectory.

The CAD/CAM has generated a growing trend in recent studies. There are different techniques involving guided surgery, evaluating accuracy of positioning of dental implants in comparison with virtual planning, and clinical results in the patients. ${ }^{[6]}$ The use of computer-guided surgery had been restricted to the advantages surgical aspects of implant treatment. Prosthetic treatment still has to be carried out following conventional protocols. However, the link to transfer prosthetic information to the patient is of great importance, and exact reference points are required to position the implants in such a way that prefabricated prosthetics have a precise fit. ${ }^{[7]}$ However, there were always deviations between virtual planning and actual outcomes in vivo location of the dental implants. ${ }^{[8]}$

Many of these techniques are already available in clinical practice and are on the way to becoming routine treatment options. It is of great importance to evaluate the accuracy that defined as the deviations in location or angle between virtual planning of computer-guided surgery and dental implants placements. ${ }^{[9]}$

Therefore, the aim of this systematic review was to assess clinical studies regarding accuracy between virtual planning of computer-guided surgery and actual outcomes of dental implant placements in total edentulous alveolar ridges.

\section{MATERIALS AND METHODS}

An electronic survey was conducted using the PubMed National Center for Biotechnology Information (National Library of Medicine National Institutes of Health) databases. The proposal was to select studies published originally in English between 2011 and 2016. The PICO (Population, Intervention, Comparison, Outcome) question was "how does static computer-guided surgery perform in terms of accuracy for placement of dental implants in edentulous patients?" [Picture 1]. Search strategy followed a combinations of keywords: "Accuracy" AND "Computer-Assisted Surgery" OR "Computer Assisted Surgery" OR "Surgery Computer Assisted" OR "Image-Guided Surgery" OR "Image Guided Surgery" OR "Image Based Surgery" OR "3D Imaging" OR "3-D Imaging "OR" Computer-Assisted 3D Imaging "OR" Dental Implants “OR" Dental Prosthesis Implantation "OR" Prosthesis Implantation “OR" Dental Implantation "OR" Dental Prosthesis “OR" Dental Prosthesis Implantations". To identify the study designs, the following terms were used: case reports, clinical study, randomized controlled trial, systematic reviews, meta-analysis, published in the last 5 years, and humans.

The selection of articles was performed by two independent reviewers (Co-author: Maurício Silva

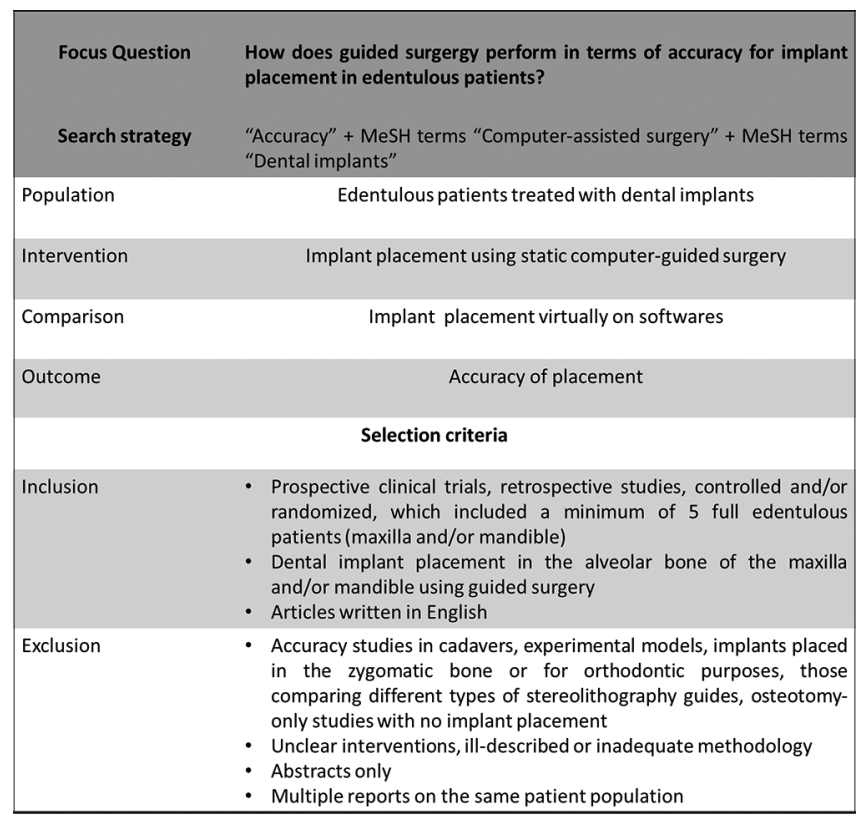

Picture 1: PICO question and selection criteria 
Demétrio (MSD) and AUTHOR: Daniel Amaral Alves Marlière (DAAM)). A manual search was performed for scientific publications in the most important journals on implant dentistry, such as Clinical Implant Dentistry and Related Research, Clinical Oral Implants Research, The International Journal of Oral and Maxillofacial Implants, Journal of Oral and Maxillofacial Surgery, Journal of Periodontology, Journal of Prosthetic Dentistry, Implant Dentistry, and The International Journal of Periodontics and Restorative Dentistry. Only articles consensually agreed by both reviewers were selected for data collection.

\section{Inclusion and exclusion criteria}

This review included studies with a number of participants $>5$, aiming at assessing the accuracy of guided surgery for the installation of dental implants in fully edentulous maxilla and mandible, based on computerized planning, with the purpose of manipulating CBCT images (pre- and postoperative), installation of dental implants virtually (CAD), and CAM stereolithographic surgical guides (CAM). The specific software for planning guided surgery allows overlapping of the CBCT images between what was planned and what was executed in the patients after the surgical procedure. The inclusion and exclusion criteria were described in Picture 1.

\section{Data collection and analysis}

The data were collected by the two blinded reviewers (DAAM and MSD), in case of disagreement, another reviewer (Revista Gaúcha de Odontologia) would be consulted. During selection and revision of the articles, the reviewers designed a table to determine the clinical characteristics to be scrutinized in each study, collecting the following information: year, type of clinical study, number of patients and implants installed, mean age, postoperative follow-up period, type of surgery (with flap or flapless), loss or failure of dental implants, and transoperative complications. Regarding evaluation of the accuracy of the dental implants installed, the reviewers provided the data of each study in a table, filling in the following information: specific software, implant system, type of guide (muco-supported stereolithography or selective laser sintering [SLS]), location of the implants, quantitative values of deviations in angulation at the cervical and apical regions, and in addition, installation error in depth.

The comparative analysis between the studies was only possible because the measuring tool for the deviations was similar [Figure 1]. Thus, this

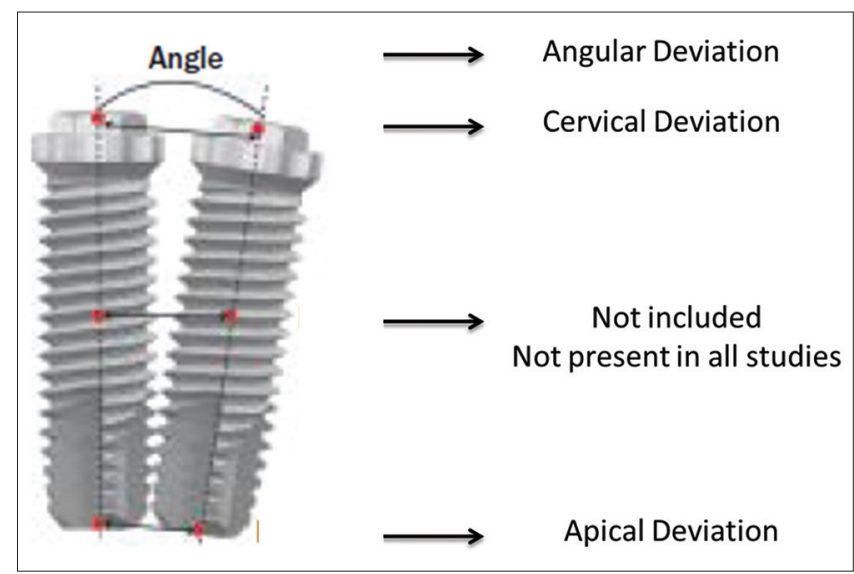

Figure 1: Illustration demonstrates the reference regions to assess the accuracy of dental implants

accuracy analysis was performed through the most common method for measuring distance between planned and actual installed dental implants, which consisted of overlays of 3D images using dedicated software [Figure 2a and b]. The most used measurement parameters in the included studies were:

- Angular deviation (measured in degrees, quantifying angulation between the longitudinal axes of the implants);

- Cervical deviation (measured on the platform or cervical region centrally between the implants);

- Apical deviation (measured in $\mathrm{mm}$ in the apical region centrally between the implants);

- Depth error (Measurement in $\mathrm{mm}$ of the apico-cervical deviation of the implants, lesser, or greater depth of insertion);

\section{RESULTS}

After the initial search, 168 article titles were identified. Analysis of the titles excluded 112 articles. Subsequently, the reviewers' shortlisted 56 abstracts from the most relevant articles. The level of agreement between the two reviewers in the study selection was substantial $(\mathrm{k}=0.767)$. After evaluation of the full articles, 49 were excluded and 7 studies fulfilled the inclusion criteria in this review. The level of agreement for eligibility was measured $(\mathrm{k}=0.883)$ and considered excellent [Figure 3].

Table 1 shows that clinical studies were published in the years 2012, 2013, and 2014, with 2 retrospective and 5 prospective studies. These studies subjected all 95 edentulous patients in the maxilla and/or mandible to guided surgery of dental implants. A total of 638 dental implants were installed, with 4 osseointegration failures detected. Most of the studies 
performed osteotomies and implant placement using guided surgery, evidencing a flapless approach and patients followed up for 12-30 months.

In Table 1, softwares for CAD/CAM were Facilitate Software (Astra Tech), Procera Software (Nobel Biocare), Implant Viewer 1.5 (Anne Solutions), Dental Slice (Bioparts), and SimPlant (Materialise Dental). The implant systems used were Nobel Biocare (Nobel Guide), Six OsseoSpeed Implants, Prime Impladent, and Astra OsseoSpeed.

Most of the studies used stereolithography and muco-supported surgical guides with pins or screws for fixation. Only Stübinger et al. in 2014 ${ }^{[10]}$ used bone-supported surgical guides using pins or screws for fixation. It is observed that the

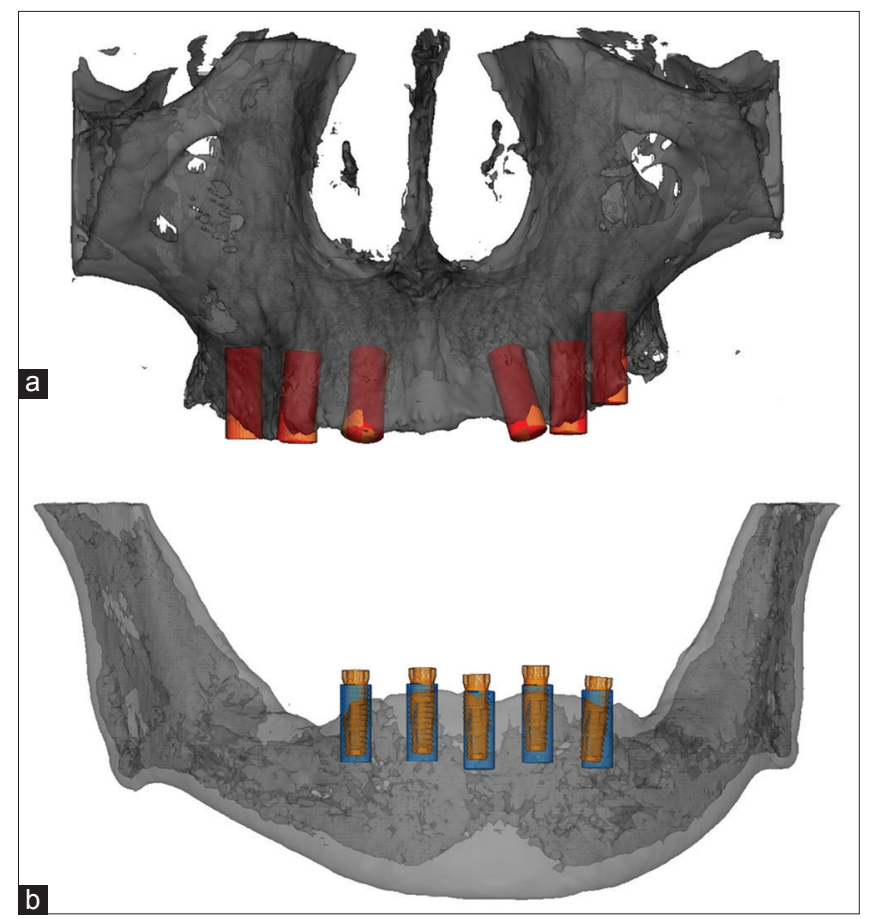

Figure 2: (a and b) Illustration demonstrates image overlap (three-dimensional) to compare and quantify the accuracy of dental implants planned and placed in the maxilla and the mandible surgical guides used by Di Giacomo et al. ${ }^{[11]}$ were manufactured by SLS, thus standardizing support and stability [Table 2].

The angular deviations at the cervical and apical areas of the installed implants were described in all clinical studies, being presented as the mean and standard deviation (SD) of the measurements, respectively [Table 2].

The mean angular deviation between the studies ranged from $1.85^{\circ}$ (minimum) to $8.4^{\circ}$ (maximum), corresponding to different locations in the alveolar ridge, namely, the mandible and the maxilla, respectively. The variation of the mean cervical deviation was $0.71 \mathrm{~mm}$ to $2.17 \mathrm{~mm}$, and such implants were placed in maxillary ridges. The mean apical deviation was $0.77 \mathrm{~mm}$ to $2.86 \mathrm{~mm}$ in maxillary ridges. Regarding implant depth error, most studies did not report these data [Table 2].

\section{DISCUSSION}

This systematic review evaluated the literature regarding the accuracy of dental implants installed

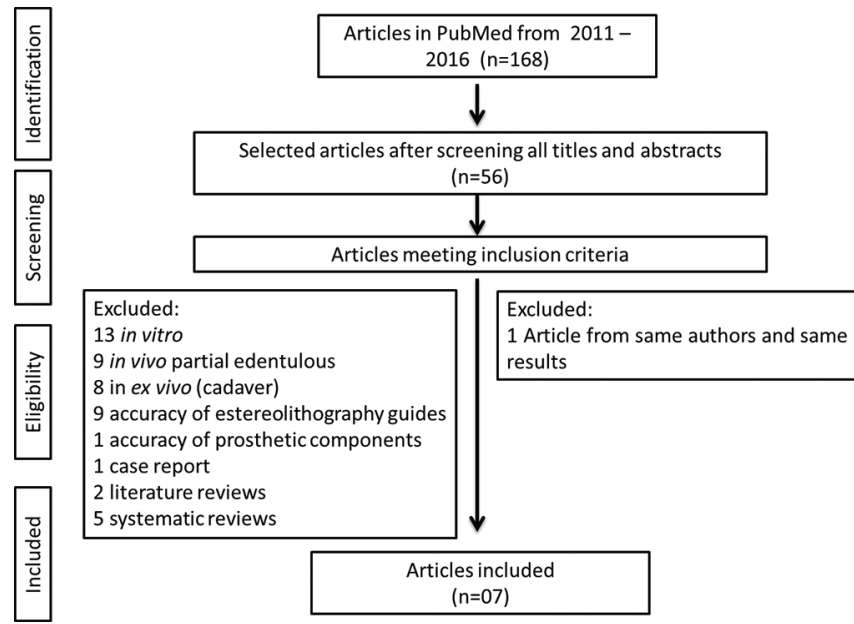

Figure 3: Flowchart of electronic search and selection of studies

Table 1: Clinical data from the accuracy studies selected on dental implants placed via guided surgery

\begin{tabular}{|c|c|c|c|c|c|c|c|c|c|}
\hline Authors & Year & $\begin{array}{l}\text { Clinical } \\
\text { study }\end{array}$ & $\begin{array}{l}\text { Patients } \\
\text { (n) }\end{array}$ & $\begin{array}{l}\text { Implants } \\
(n)\end{array}$ & $\begin{array}{l}\text { Mean age } \\
\text { (IV)* }\end{array}$ & $\begin{array}{l}\text { Follow-up } \\
\text { (months) }\end{array}$ & $\begin{array}{l}\text { Flapless } \\
\text { surgery }\end{array}$ & $\begin{array}{c}\text { Implant } \\
\text { failures }(n)\end{array}$ & $\begin{array}{l}\text { Transoperative } \\
\text { complications }\end{array}$ \\
\hline D'haese et al. & 2012 & Prospective & 13 & 78 & $53.3(36-72)$ & 12 & Yes & 01 & NR \\
\hline Giacomo et al. & 2012 & Prospective & 12 & 60 & NR (41-71) & 30 & Yes & 03 & NR \\
\hline Pettersson et al. & 2012 & Retrospective & 11 & 139 & $72(44-92)$ & 12 & Yes & NR & NR \\
\hline Vieira et al. & 2013 & Prospective & 14 & 62 & NR & NR & Yes & NR & NR \\
\hline Ochi et al. & 2013 & Prospective & 15 & 30 & NR & 12 & Yes & NR & NR \\
\hline Cassetta et al. & 2014 & Retrospective & 20 & 225 & $\mathrm{NR}$ & $N R$ & Yes & NR & NR \\
\hline Strübinger et al. & 2014 & Prospective & 10 & 44 & $62,5(47-81)$ & 12 & No & NR & NR \\
\hline
\end{tabular}


Marlière, et al.: Accuracy computer-guided surgery dental implant

\begin{tabular}{|c|c|c|c|c|c|c|c|c|}
\hline Authors & $\begin{array}{l}\text { Software } \\
\text { (CAD) }\end{array}$ & $\begin{array}{l}\text { Implant } \\
\text { System }\end{array}$ & $\begin{array}{l}\text { Guide type } \\
\text { (SLA and SLS) }\end{array}$ & Location & $\begin{array}{l}\text { Angular deviation } \\
\left({ }^{\circ}\right) \text { mean (SD) }\end{array}$ & $\begin{array}{c}\text { Cervical } \\
\text { deviation }(\mathrm{mm}) \\
\text { mean }(\mathrm{SD})\end{array}$ & $\begin{array}{c}\text { Apical } \\
\text { deviation }(\mathrm{mm}) \\
\text { mean }(\mathrm{SD})\end{array}$ & $\begin{array}{c}\text { Depth } \\
\text { error }(\mathrm{mm}) \\
\text { mean }(\mathrm{SD})\end{array}$ \\
\hline $\begin{array}{l}\text { D'haese } \\
\text { et al. }\end{array}$ & Facilitate & $\begin{array}{l}\text { Six } \\
\text { OsseoSpeed } \\
\text { Implants }\end{array}$ & $\begin{array}{l}\text { Muco-supported } \\
\text { SLA with } \\
\text { fixation }\end{array}$ & Maxilla & $2.6^{\circ}\left(+-1.61^{\circ}\right)$ & $0.91(+-0.44)$ & $1.13(+-0.52)$ & $\mathrm{NR}$ \\
\hline $\begin{array}{l}\text { Di } \\
\text { Giacomo } \\
\text { et al. }\end{array}$ & $\begin{array}{l}\text { Implant } \\
\text { Viewer }\end{array}$ & $\begin{array}{l}\text { Nobel } \\
\text { Biocare } \\
\text { (Guide) }\end{array}$ & $\begin{array}{l}\text { Muco-supported } \\
\text { SLS with } \\
\text { fixation }\end{array}$ & $\begin{array}{l}\text { Maxilla } \\
\text { mandible }\end{array}$ & $\begin{array}{c}6.53^{\circ}(-) \\
8.4^{\circ}\left(+-4.20^{\circ}\right) \\
5.37^{\circ}\left(+-3.98^{\circ}\right)\end{array}$ & $\begin{array}{l}1.35(+-0.65) \\
1.51(+-0.62) \\
1.26(+-0.66)\end{array}$ & $\begin{array}{l}1.79(+-1.01) \\
1.86(+-1.07) \\
1.75(+-0.99)\end{array}$ & NR \\
\hline $\begin{array}{l}\text { Pettersson } \\
\text { et al. }\end{array}$ & Procera & $\begin{array}{l}\text { Nobel } \\
\text { Biocare } \\
\text { (Guide) }\end{array}$ & $\begin{array}{l}\text { Muco-supported } \\
\text { SLA with } \\
\text { fixation }\end{array}$ & $\begin{array}{l}\text { Maxilla } \\
\text { mandible }\end{array}$ & $\begin{array}{c}2.26^{\circ}\left(+-2.01^{\circ}\right) \\
2.31^{\circ}\left(0.24^{\circ}-6.96^{\circ}\right) \\
2.16^{\circ}\left(0.27^{\circ}-11.74^{\circ}\right)\end{array}$ & $\begin{array}{c}0.80(+-0.72) \\
0.80(0.10-2.68) \\
0.80(0.16-2.45)\end{array}$ & $\begin{array}{c}1.09(+-1.01) \\
1.05(0.21-3.62) \\
1.15(0.24-3.63)\end{array}$ & $\begin{array}{l}-0.15(-2.33-2.05) \\
-0.06(-1.65-2.05) \\
-0.29(-2.33-0.94)\end{array}$ \\
\hline $\begin{array}{l}\text { Vieira } \\
\text { et al. }\end{array}$ & $\begin{array}{l}\text { Dental } \\
\text { Slice }\end{array}$ & $\begin{array}{l}\text { Nobel } \\
\text { Biocare } \\
\text { (Guide) }\end{array}$ & $\begin{array}{l}\text { Muco-supported } \\
\text { SLA with } \\
\text { fixation }\end{array}$ & $\begin{array}{l}\text { Maxilla } \\
\text { mandible }\end{array}$ & $\begin{array}{l}1.93^{\circ}\left(+-0.17^{\circ}\right) \\
1.85^{\circ}\left(+-0.75^{\circ}\right)\end{array}$ & $\begin{array}{l}2.17(+-0.87) \\
1.42(+-0.71)\end{array}$ & $\begin{array}{l}2.86(+-2.17) \\
1.57(+-0.84)\end{array}$ & NR \\
\hline Ochi et al. & Procera & $\begin{array}{l}\text { Nobel } \\
\text { Biocare } \\
\text { (Guide) }\end{array}$ & $\begin{array}{l}\text { Muco-supported } \\
\text { SLA with } \\
\text { fixation }\end{array}$ & Mandible & NR & $0.89(+-0.44)$ & $1.08(+-0.47)$ & $\begin{array}{l}21 \text { superficial } \\
\text { implants } 9 \\
\text { deep implants }\end{array}$ \\
\hline $\begin{array}{l}\text { Cassetta } \\
\text { et al. }\end{array}$ & SimPlant & $\begin{array}{l}\text { Prime } \\
\text { Impladent }\end{array}$ & $\begin{array}{l}\text { Muco-supported } \\
\text { SLA with } \\
\text { fixation" No } \\
\text { fixation§ }\end{array}$ & $\begin{array}{l}\text { Maxillamx }^{m x} \\
\text { Mandible }^{m d}\end{array}$ & $\begin{array}{c}4.67^{\circ}\left(+-2.68^{\circ}\right) \\
\# 4.09^{\circ}\left(+-2.40^{\circ}\right) \\
\$ 5.62^{\circ}\left(+-2.80^{\circ}\right) \\
{ }^{m \times} 4.36^{\circ}\left(+-2.9^{\circ}\right) \\
{ }^{\circ} 5.46^{\circ}\left(+-2.03^{\circ}\right)\end{array}$ & $\begin{array}{c}1.68(+-0.6) \\
\# 1.66(+-0.58) \\
\$ 1.68^{\circ}(+-0.60) \\
m \times 1.68(+-0.51) \\
m d 1.64(+-0.71)\end{array}$ & 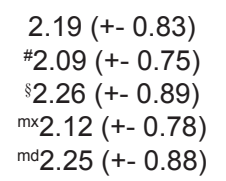 & NR \\
\hline $\begin{array}{l}\text { Strübinger } \\
\text { et al. }\end{array}$ & Facilitate & $\begin{array}{l}\text { Astra } \\
\text { OsseoSpeed }\end{array}$ & $\begin{array}{l}\text { Bone-supported } \\
\text { SLA with } \\
\text { fixation }\end{array}$ & Maxilla & $2.39^{\circ}\left(+-0.97^{\circ}\right)$ & $0.71(+-0.399)$ & $0.77(+-0.382)$ & $0.47(+-0.496)$ \\
\hline
\end{tabular}

using the static method of computer-guided surgery, exclusively in patients (in vivo) with edentulous maxillary and mandibular alveolar ridges. Studies in phantom models (in vitro) were excluded from the accuracy assessment because the deviations described therein were presumably related to thecomputer-guided surgery workflow (errors accumulated during CBCT image acquisition and data processing in softwares, stereolithographic surgical templates production, and tolerance of the guiding sleeve).$^{[8,12,13]}$ It is worth mentioning that studies in models guarantee greater stability of the surgical guides, safety in executing the osteotomy, and consequently, implant placement when compared to the oral cavity because in these models, there is no floor of the mouth, tongue, buccal mucosa, or buccal sulcus, which may lead to greater instability of the guide. ${ }^{[14]}$

Other studies identified and excluded were performed on cadavers (ex vivo), however, methods of preserving cadavers can alter bone structure, interfere with the use of surgical guides, and consequently, the accuracy of dental implant placement. Noharet et al. ${ }^{[15]}$ reported that the use of cadavers preserved in formalin may generate significant inaccuracy since this chemical method causes demineralization, affecting dental implant placement. These authors further argued that preservation by freezing is the closest to clinical conditions. However, this physical method could alter the properties of the mucosa, and thus interfere with the adjustment of the surgical guides, probably increasing deviations during implant installation. Thus, it would not be logical to compare deviations measurements between studies in vivo, ex vivo, and in vitro.

Jung et al. ${ }^{[3]}$ performed a systematic review on accuracy based on studies of computer-guided surgery for the installation of dental implants. In general, observed that accuracy was better in in vitro and in ex vivo models compared to in vivo studies. In this sense, better access, visualization and control of the osteotomy axis, absence of patient movements, and no saliva and bleeding were the factors presented by these authors to explain that greater deviations was found in clinical studies in vivo. Nowadays, these concepts still persist for Bover-Ramos et al..$^{[9]}$ did a systematic review and meta-analysis to analyze the accuracy of implant placement using computer-guided surgery and to compare virtual planning and outcome regarding to study type (in vitro, cadaver, or clinical). Implant placement accuracy was lower in clinical and cadaver studies compared with in vitro studies, especially in terms of apical and angular deviations.

The literature presents a limited number of studies that discuss the variables capable of causing deviations 
between the virtually planned position and implant placement using stereolithography guides. ${ }^{[16]}$ It can be emphasized that during acquisition, processing, and manipulation of images an error of approximately $0.5 \mathrm{~mm}$ may occur, ${ }^{[17]}$ and incorrect configurations in software can generate slight deformations in surgical guides, varying from 0.1 to $0.2 \mathrm{~mm} \cdot{ }^{[18]}$ For Stumpe ${ }^{[13]}$ errors could also occur during the manufacturing of the surgical guide in the phase of surgical simulation on the software, in the precision of the prototyping machine, in the properties of the stereolithography material used, in the fit between the cylinders of the guide, drills, and washers of the implant systems.

Manufacturing errors of the guide can have a cumulative effect, which can generate unfavorable clinical results. ${ }^{[16]}$ However, errors are not exclusive of the workflow process and/or the product itself (stereolithographic surgical guide). The type of surgical guide (dento-supported, muco-supported with or without bone-supported fixation), as well as morphological factors of the peri-implant tissues (bone type: cortical or medullary, thickness of gingival mucosa), may interfere in the accuracy between what was planned and the actual outcomes of dental implants placement.

To minimize possible inaccuracy in the installation of dental implants by guided surgery, D'haese et al..$^{[8]}$ used muco-supported guides appropriately adjusted to the mucosal surface and fastened with screws, noting that the mean results of deviations (angular: $2.6^{\circ}$, cervical: $0.91 \mathrm{~mm}$, and apical: $1.13 \mathrm{~mm}$ ) were lower than those reported by previous studies (angular: $7.9^{\circ}$, cervical: $1.4 \mathrm{~mm}$, and apical: $1.6 \mathrm{~mm}) \cdot{ }^{[19]}$ In this sense, Cassetta et al. ${ }^{[20]}$ evaluated the precision of muco-supported surgical guides with and without fixation screws in the edentulous edges of the maxilla and mandible. In a paired comparison between the means of the deviations (with or without fixation), they showed that the fixed guides resulted in better precision of implant placement, which was statistically significant for angular deviation (angular: with- $4.09^{\circ}$, without- $5 \cdot 62^{\circ}$ ). It may be, therefore, concluded that fixation of the surgical guides allows greater transoperative stability, reducing errors between the planned and the executed treatment.

Stübinger et al. ${ }^{[10]}$ used a screw-fixed bone-supported guide in an open flap surgical approach [Table 1]. The authors pointed out that there is a trend to greater deviation with muco-supported guide compared to those used in this study. This is described in Table 2 by assessing mean values of cervical and apical deviation, respectively, $0.71 \mathrm{~mm}(\mathrm{SD} \pm 0.399)$ and $0.77 \mathrm{~mm}(\mathrm{SD} \pm 0.382$ ), representing the lowest deviations among all the reviewed studies consisting of installing dental implants in edentulous maxillary ridges. The lowest deviations in that study may be related to support of surgical guides on bone and not on gingival or alveolar mucosa. Vasak et al. ${ }^{[21]}$ demonstrated that there is a significant correlation between mucosa thickness at the implant insertion site and the degree of deviation since the thickness affects the reproducibility of positioning as well as the stability of the guide.

However, the mean of angular deviation value $\left(2.39^{\circ}-S D \pm 0.97^{\circ}\right)$ would not represent greater accuracy in implant placement since Pettersson et al. ${ }^{[22]}$ and Vieira et al. ${ }^{[23]}$ reported angular deviations of $1.93^{\circ}\left(\mathrm{DP} \pm 0.17^{\circ}\right)$ and $2.31^{\circ}\left(0.24^{\circ}-6.96^{\circ}\right)$, respectively. Regardless of the deviations reported by such studies, Stübinger et al..$^{[10]}$ used guides adapted to bone, by means of an incision and a mucoperiosteal flap, reporting some disadvantages to this type of approach for computer-guided surgery, especially with regards to trans- and postoperative morbidity.

Another important aspect to highlight is the bone structure itself, which if predominantly medullary (maxilla) would have greater impact on the deviations between planning and execution. This is due probably to lower resistance to torque, when compared to cortical bone, which in turn causes more pronounced deviations in the position of the dental implants. ${ }^{[10]}$ This observation is further illustrated in more specifically, the results by Di Giacomo et al. ${ }^{[11]}$ Vieira et al., ${ }^{[23]}$ and Cassetta et al. ${ }^{[20]}$

In Table 2, the mean apical deviation values were higher than at the cervical region (implant shoulder). D'haese et al. ${ }^{[8]}$ highlighted that if deviation in angulation occurred, by mathematical reasoning, there should be greater deviation at the apex of the implants. For Vieira et al. ${ }^{[23]}$ and Cassetta et al. ${ }^{[20]}$ apical deviations raise concerns since $2 \mathrm{~mm}$ discrepancies between planning and execution can be considered clinically significant, as in certain circumstances, a safety margin around vital structures is recommended. These authors have argued that apical deviations are dependent on mucosal thickness and morphological type of bone structure, that is, the resilience of the mucosa in edentulous arches causes a clinically imperceptible misfit in the adaptation of the guide (even with fixation), and medullary bone allows for less mechanical compression, facilitating 
deviations at the osteotomy sites, and changes to the dental implant placement trajectory. Nevertheless, even studies using bone supported guides with fixation demonstrated that achieving accuracy is always more difficult apically. ${ }^{[10]}$

According to the studies summarized in Table 2, all showed deviations between the virtual planning and actual outcomes of dental implant placement. In this context, would such deviations make it impossible to rehabilitate patients? Although deviations between planning and implants placement could be substantial, it would not adversely affect the restorative steps if any prosthetic workflow was performed after implant placement. ${ }^{[23]}$ In some studies, the prosthesis framework was fabricated before implant installation, based on virtual planning. In these cases, deviations could result in impaired rehabilitation of edentulous patients because the inaccuracy between the planning and actual outcomes of the implants placement could lead to prosthetic complications, such as misalignments, need for extensive occlusal adjustments, and bone margin overload. ${ }^{[23]}$

Moreover, deviations may create some problems intraoperative (close proximity to vital structures such vessel and nerves) ${ }^{[23]}$ and postoperative conditions, as unfavorable results might be related with technical difficulties of the prosthesis framework, patient's discomfort, and long-term clinical insuccess. ${ }^{[24]}$ In this sense, deviations of implants placement regarding the prosthesis may be a problem when stress distribution loads and masticatory forces involve rehabilitation replacing dental and cannot withstand repeated loads cycles, so there being failure by fatigue of prosthetic components. ${ }^{[25]}$

During the last years, scientific investigation had given a good qualitative contribution in the knowledge of the distribution of stress and strain for evaluation of an adequate stability of the dental implant osseointegrated. ${ }^{\left[{ }^{[6]}\right.}$ However, there must be very careful to approach problems of implants related prosthesis.

For offering better performance and have long-term results, Cicciù et al. ${ }^{[24]}$ used the methodology finite element analysis in implant dentistry to help preventing possible errors due to incorrect operation system, understand the distribution of stress and strain in maxilla and mandibular bones with osseointegrated implants, and material characteristics as physical and chemical properties of the prosthetic dental components. The authors applied finite element analysis in dental implants that presented a microthread part on the neck. The finite element analysis was performed with a tensile load and bending moment (vertical, lateral, and occlusal load) that allowed flexion-strength condition (typical of the prosthesis edentulous patient's) on the dental implants, prosthesis components, and marginal bone. The results suggested which components prosthesis of dental implants (different geometry of the neck) had values tensions higher than fatigue limits of the material even fixture and for the abutment. Therefore, it is important to enable appropriates choices of the clinicians and implant industry about surface features and geometric shape more proper to each clinical situation.

It is clear that the accuracy of computer-guided surgery depends on the cumulative effect and interaction of the errors gathered along the entire workflow process, from image acquisition through to the execution of the surgical procedure. In addition, as concluded in the ITI systematic review in 2008, ${ }^{[3]}$ dental implants rehabilitation using computer-guided surgery is feasible, though the findings of the present study have suggested that there would be no evidence to support the superiority of computer-guided surgery over conventional procedures in terms of safety and optimization of clinical results.

\section{CONCLUSIONS}

As observed in this systematic review addressed clinical studies, different computer-guided surgery implant systems were described in the literature. For angular deviation, obtained most inaccuracy in maxilla (mean $8,4^{\circ}, \mathrm{SD} \pm 4,2^{\circ}$ ). For cervical and apical deviations, accuracy was preponderantly lower in maxilla. Despite the similar deviations measurement approaches described, clinical relevance of this study may be useful to warn the surgeon that safety margins to consider should refer to clinical situations.

\section{Financial support and sponsorship}

Nil.

\section{Conflicts of interest}

There are no conflicts of interest.

\section{REFERENCES}

1. Widmann G, Bale RJ. Accuracy in computer-aided implant surgery - A review. Int J Oral Maxillofac Implants 2006;21:305-13.

2. Loubele M, Van Assche N, Carpentier K, Maes F, Jacobs R, 
van Steenberghe D, et al. Comparative localized linear accuracy of small-field cone-beam CT and multislice CT for alveolar bone measurements. Oral Surg Oral Med Oral Pathol Oral Radiol Endod 2008;105:512-8.

3. Jung RE, Schneider D, Ganeles J, Wismeijer D, Zwahlen M, Hämmerle $\mathrm{CH}$, et al. Computer technology applications in surgical implant dentistry: A systematic review. Int J Oral Maxillofac Implants 2009;24 Suppl:92-109.

4. Kupeyan HK, Shaffner M, Armstrong J. Definitive CAD/CAM-guided prosthesis for immediate loading of bone-grafted maxilla: A case report. Clin Implant Dent Relat Res 2006;8:161-7.

5. Hämmerle CH, Stone P, Jung RE, Kapos T, Brodala N. Consensus statements and recommended clinical procedures regarding computer-assisted implant dentistry. Int J Oral Maxillofac Implants 2009;24 Suppl:126-31.

6. Tahmaseb A, Wismeijer D, Coucke W, Derksen W. Computer technology applications in surgical implant dentistry: A systematic review. Int J Oral Maxillofac Implants 2014;29 Suppl:25-42.

7. Tahmaseb A, De Clerck R, Aartman I, Wismeijer D. Digital protocol for reference-based guided surgery and immediate loading: A prospective clinical study. Int J Oral Maxillofac Implants 2012;27:1258-70.

8. D'haese J, Van De Velde T, Elaut L, De Bruyn H. A prospective study on the accuracy of mucosally supported stereolithographic surgical guides in fully edentulous maxillae. Clin Implant Dent Relat Res 2012;14:293-303.

9. Bover-Ramos F, Viña-Almunia J, Cervera-Ballester J, Peñarrocha-Diago M, García-Mira B. Accuracy of implant placement with computer-guided surgery: A Systematic review and meta-analysis comparing cadaver, clinical, and in vitro studies. Int J Oral Maxillofac Implants 2017; doi: 10.11607/jomi.5556. [Epub ahead of print].

10. Stübinger S, Buitrago-Tellez C, Cantelmi G. Deviations between placed and planned implant positions: An accuracy pilot study of skeletally supported stereolithographic surgical templates. Clin Implant Dent Relat Res 2014;16:540-51.

11. Di Giacomo GA, da Silva JV, da Silva AM, Paschoal GH, Cury PR, Szarf G, et al. Accuracy and complications of computer-designed selective laser sintering surgical guides for flapless dental implant placement and immediate definitive prosthesis installation. J Periodontol 2012;83:410-9.

12. Chang PS, Parker TH, Patrick CW Jr., Miller MJ. The accuracy of stereolithography in planning craniofacial bone replacement. J Craniofac Surg 2003;14:164-70.

13. Stumpel LJ. Deformation of stereolithographically produced surgical guides: An observational case series report. Clin Implant Dent Relat Res 2012;14:442-53.

14. Ochi M, Kanazawa M, Sato D, Kasugai S, Hirano S, Minakuchi S, et al. Factors affecting accuracy of implant placement with mucosa-supported stereolithographic surgical guides in edentulous mandibles. Comput Biol Med 2013;43:1653-60.

15. Noharet R, Pettersson A, Bourgeois D. Accuracy of implant placement in the posterior maxilla as related to 2 types of surgical guides: A pilot study in the human cadaver. J Prosthet Dent 2014;112:526-32.

16. Cassetta M, Di Mambro A, Giansanti M, Stefanelli LV, Cavallini C. The intrinsic error of a stereolithographic surgical template in implant guided surgery. Int J Oral Maxillofac Surg 2013;42:264-75.

17. Reddy MS, Mayfield-Donahoo T, Vanderven FJ, Jeffcoat MK A comparison of the diagnostic advantages of panoramic radiography and computed tomography scanning for placement of root form dental implants. Clin Oral Implants Res 1994;5:229-38.

18. van Steenberghe D, Naert I, Andersson M, Brajnovic I, Van Cleynenbreugel J, Suetens $\mathrm{P}$, et al. A custom template and definitive prosthesis allowing immediate implant loading in the maxilla: A clinical report. Int J Oral Maxillofac Implants 2002;17:663-70.

19. Valente F, Schiroli G, Sbrenna A. Accuracy of computer-aided oral implant surgery: A clinical and radiographic study. Int J Oral Maxillofac Implants 2009;24:234-42.

20. Cassetta M, Giansanti M, Di Mambro A, Stefanelli LV. Accuracy of positioning of implants inserted using a mucosa-supported stereolithographic surgical guide in the edentulous maxilla and mandible. Int J Oral Maxillofac Implants 2014;29:1071-8.

21. Vasak C, Watzak G, Gahleitner A, Strbac G, Schemper M, Zechner W, et al. Computed tomography-based evaluation of template (NobelGuide ${ }^{\mathrm{TM}}$ )-guided implant positions: A prospective radiological study. Clin Oral Implants Res 2011;22:1157-63.

22. Pettersson A, Komiyama A, Hultin M, Näsström K, Klinge B. Accuracy of virtually planned and template guided implant surgery on edentate patients. Clin Implant Dent Relat Res 2012;14:527-37.

23. Vieira DM, Sotto-Maior BS, Barros CA, Reis ES, Francischone CE Clinical accuracy of flapless computer-guided surgery for implant placement in edentulous arches. Int J Oral Maxillofac Implants 2013;28:1347-51.

24. Cicciù M, Bramanti E, Cecchetti F, Scappaticci L, Guglielmino E, Risitano G, et al. FEM and Von Mises analyses of different dental implant shapes for masticatory loading distribution. Oral Implantol (Rome) 2014;7:1-0.

25. Bramanti E, Cervino G, Lauritano F, Fiorillo L, D'Amico C, Sambataro S, et al. FEM and Von Mises analysis on prosthetic crowns structural elements: Evaluation of different applied materials. ScientificWorldJournal 2017;2017:1029574.

26. Sannino G, Marra G, Feo L, G Vairo, Barlattani A 3D finite element non linear analysis on the stress state at bone-implant interface in dental osteointegrated implants. Oral Implantol (Rome) 2010;3:26-37. 